The incidence of psychological disorder found in this survey is probably higher than among university students as a whole. Although comparison with other studies may be misleading because of differences in method or diagnostic criteria, the higher figure may perhaps be due to preclinical medical students' being exposed to special stresses over and above those which are common to all students.

To a greater or less extent that varies from one medical school to another the preclinical student continues to lead the life of a schoolboy and is given little or no freedom of choice in attendance at lectures and manner of work. $\mathrm{He}$ can attain more freedom and responsibility only by passing the 2nd M.B. Anxiety before examinations is probably the commonest cause of psychological upset among students of all faculties, ${ }^{2}$ but of all exams taken by medical students the 2nd M.B. is the most difficult and harassing. Memory often has to play a greater part than understanding, many of the facts to be learned are boring, and some parts of the syllabus may seem to have virtually no relevance to future clinical work. Behind all the student's learning lurks fear of failure, of disappointed parents, of time and money wasted, and the final abandonment of all his hopes of a medical career.

However, only a third of the students surveyed developed psychological symptoms. Comparing these with symptomfree students showed no significant differences in intelligence or structure of personality, but did show a poorer record of health while undergraduates and in their last year at school. The authors of the survey conclude from this that students with psychological symptoms are reacting to stresses in a way which is an extension and amplification of an earlier pattern of reactions. This may well be so, particularly if they still see themselves as schoolchildren struggling towards the promised land. What seems more important is that by this information it may be possible to pick out and therefore help at an early stage the student predisposed to develop excessive anxiety.

It is not always appreciated how superficial the origin of an anxiety state may be and how easily and quickly it may be dealt with in the early stages. Yet, as was stated five years ago ${ }^{3}$ for this to be possible better facilities to guard the mental health of students are needed than exist in many centres to-day.

\section{The Sarcoidosis Controversy}

In spite of increasing knowledge of sarcoidosis its aetiology remains controversial. Particularly hotly disputed is the role of infection by Mycobacterium tuberculosis and of other mycobacteria in the causation of the disease. New facts relevant to this question have now been given by Drs. I. Sutherland, D. N. Mitchell, and P. D'Arcy Hart in their detailed analysis, printed in last week's B.M.7., of data from the Medical Research Council's tuberculosis vaccines trial. ${ }^{1}$

Over 54,000 persons aged about 14 years were tuberculintested on entry to the trial. Those who had a negative reaction to 100 tuberculin units (T.U.) were given tuberculosis vaccination or were left unvaccinated according to random

\footnotetext{
1 Lucas, C. J., Kelvin, R. P., and Ojha, A. B., Brit. F. Psychiat., 1965, $111,473$.

Malleson, N., Brit. med. F., 1957, 2, 551.

Ibid., 1960, 2, 851 .
}

selection. Those who on entry to the trial were tuberculinpositive were grouped into those positive to $3 \mathrm{~T}$.U. and those negative to 3 T.U. but positive to 100 T.U. All groups were similarly and thoroughly followed up by annual miniature chest radiography, tuberculin tests, postal inquiries, and home visits for more than 10 years. During this time 52 cases of intrathoracic sarcoidosis were discovered.

Comparison of the observed incidence of intrathoracic sarcoidosis in the various groups showed that vaccination against tuberculosis at the age of about 14 years did not protect against sarcoidosis during the next decade, although it was effective in preventing tuberculosis. Nor did vaccination against tuberculosis promote sarcoidosis. Those children who on entry to the trial had positive reactions to tuberculin (whether the degree of sensitivity was strong or weak) had an incidence of sarcoidosis which was similar to that of children who showed no such evidence of mycobacterial infection. The age and sex and geographical distributions of the attack rates of sarcoidosis were different from those of tuberculosis in the same population.

These observations do not support the hypothesis that sarcoidosis is a reaction to mycobacterial infection. Nevertheless, there is well-documented evidence that some cases of sarcoidosis are a manifestation of tuberculous infection. ${ }^{2}$ The development of sarcoidosis rather than caseating tuberculosis in response to infection with $M$. tuberculosis has been attributed to a peculiarity of the tissue reactivity of the patient at the time of infection. ${ }^{2}{ }^{3}$ Thus, the elucidation of the aetiology of sarcoidosis requires a study of the tissue reactivity of the host as well as a search for external causative agents. Patients with sarcoidosis show a poor response of the delayed type of immunological reactions in general. A particular example of this is that they are usually not tuberculin-sensitive and they show failure to convert after B.C.G. vaccination..$^{4-6}$ This immunological defect may be the result of sarcoidosis, or it might be present before the onset of the disease. It is therefore of special interest to know whether patients who develop sarcoidosis are or are not tuberculin-sensitive before the onset of their disease. The M.R.C. trial provides an answer to this question. The tuberculin sensitivity of the group of patients who developed intrathoracic sarcoidosis (determined by tests done before the onset of their disease) was similar to that of the group who did not develop the disease. Further, patients who developed sarcoidosis after tuberculous vaccination showed normal tuberculin conversion. Tuberculin sensitivity tended to be depressed in patients with sarcoidosis only at and after the onset of their disease. These findings do not disprove the possibility that some people may have an abnormal reactivity of the tissues which may predispose to the development of sarcoidosis, but they do suggest that the abnormality may not be elicited by tuberculin testing.

Another test of abnormal tissue reactivity in sarcoidosis is the Kveim test, which produces a characteristic granulomatous response. $^{78}$ Children in the M.R.C. trial who failed to develop tuberculin sensitivity after two B.C.G. vaccinations

\footnotetext{
Sutherland, I., Mitchell, D. N., and Hart, P. D'A., Brit. med. F., 1965, 2, 497.

2 Scadding, J. G., ibid., 1960, 2, 1617

s Citron, K. M., and Scadding, J. G., Quart. F. Med., 1957, 26, 277.

- Sones, M., and Israel, H. L., Ann. intern. Med., 1954, 40, 260.

- Citron, K. M., Tubercle (Lond.), 1957, 38, 33.

- Lemming, R., Acta med. scand., 1940, 103, 400.

Siltzbach, L. E., Amer Rev. resp. Dis., 1961, 84, Suppl. (November), p. 89.

- James, D. G., and Thomson, A. D., Quart. F. Med., 1955, 24, 49.

y Hart, P. D'A., Mitchell, D. N., and Sutherland, I., Brit. med. f., 1964, 1, 795 .
} 
but who were apparently healthy and showed no clinical evidence of sarcoidosis were given Kveim tests, ${ }^{9}$ and a high proportion had positive reactions to them. The association of failure to respond to tuberculin with positive Kveim tests in these subjects is unexplained and is being investigated further. This new study may throw further light on the vexed question of the aetiology of sarcoidosis.

\section{Mallory-Weiss Syndrome}

In 1929 G. K. Mallory and S. Weiss ${ }^{1}$ described 15 patients with alcoholism who showed a consistent pattern of symptoms after an alcoholic bout. They developed nausea, retched, and vomited clear fluid which was often mixed with food. Finally they vomited blood. Necropsies on four of these patients showed linear lacerations of the cardiac opening of the stomach. The finding of a similar lesion in a patient with hyperemesis gravidarum led them to suggest that the laceration might have been related to vomiting. During vomiting the intragastric pressure rises, the diaphragm descends, and the gastro-oesophageal sphincter becomes incompetent, so that reflux of the gastric contents may occur. Mallory and Weiss considered that if the gastro-oesophageal opening remained closed (owing to muscular incoordination) the raised pressure within the stomach might produce the lacerations. Thus distension of the stomach against an occluded oesophagus in cadavers was found to produce the typical longitudinal tears.

As more cases have been reported the clinical picture of this syndrome has become clearer. It does not occur only in alcoholics, and, though it may be due to vomiting in conditions such as alcoholism, migraine, pancreatitis, travel sickness, and uraemia, violent contractions of the muscles of the abdomen and diaphragm during status asthmaticus, paroxysms of coughing, and epileptic convulsions are other causes. $^{2}$ The presence of atrophic gastritis probably increases the predisposition of the stomach to such lacerations. ${ }^{14}$ Nevertheless, a history of these precipitating factors is not always obtained, and indeed the first vomit may be bloodstained. ${ }^{2}{ }^{3}$

Clearly a tear may be produced without causing bleeding if it does not penetrate a major blood-vessel. Furthermore, bleeding may be small in amount and stop spontaneously. On the other hand, if the laceration transects the entire thickness of the gastro-oesophageal wall a spontaneous perforation of the oesophagus occurs and there is the risk of dangerous mediastinitis. ${ }^{5}$

With increasing awareness of its existence the MalloryWeiss syndrome is now being diagnosed more frequently in patients with haemorrhage from the gut. Thus it was

1 Mallory, G. K., and Weiss, S., F. Amer. med. Ass., 1929, 178, 506.

${ }^{2}$ Atkinson, M., Bottrill, M. B., Edwards, A. T., Mitchell, W. M., Peet, B. G., and Williams, R. E., Gut, 1961, $2,1$.

${ }^{3}$ Freeark, R. J., Narcoss, W. J., Baker, R. J., and Strohl, E. L., Arch. Surg., 1964, 88, 882.

- Decker, J. P., Zamcheck, N., and Mallory, G. K., New Engl. F. Med., 1953, 249, 957.

'Mackler, S. A., Surg. Gynec. Obstet., 1952, 95, 345.

- Palmer, E. D., Ann. intern. Med., 1952, 36, 1484.

'Chalmers, T. C., Zamcheck, N., Curtiss, J. W., and White, F. W., Amer. F. clin. Path., 1952, 22, 634.

${ }^{8}$ Byrne, J. J., and Moran, J. M., New Engl. F. Med., 1965, 272, 398.

Jones, F. Avery, Gastroenterology, 1956, 30, 166.

10 Shuttleworth, K. E. D., and Hutt, M. S. R., Brit. F. Surg., 1958, 46, 1. suspected in 7 out of 121 patients investigated by E. D. Palmer $^{6}$; in 3 of 101 reported by T. C. Chalmers and his colleagues $^{7}$; and more recently, after an initial case had been diagnosed, $M$. Atkinson and his colleagues made this diagnosis in 4 out of 73 consecutive patients with haematemesis. ${ }^{2}$ Three patients with this syndrome were seen within 32 days in one hospital in the U.S.A. ${ }^{s}$ Probably the condition is responsible for many of the $20 \%$ of cases of haematemesis for which no apparent cause can be found. ${ }^{9}$

There may be no specific diagnostic features of the syndrome, though the lacerations may occasionally be seen at gastroscopy. ${ }^{26}$ Bleeding is often not controlled by oesophagogastric compression with the Sengstaken tube. ${ }^{3}$ If no cause for haematemesis is found at laparotomy a wide gastrotomy with direct inspection of the cardiac orifice is necessary before the syndrome can be excluded. If any lacerations are found they should be sutured. ${ }^{2} 38$ On the other hand, if gastrectomy is performed without inspection of the interior of the stomach the lacerations will be missed and a second laparotomy may be necessary. ${ }^{10}$

\section{Phaeochromocytoma and Thyroid Cancer}

A causal connexion between two diseases is often difficult to prove, especially when both are fairly common. But for rarer conditions it should be easier both to recognize such an association and to establish its significance. At first sight a link between phaeochromocytoma, which is a tumour of the adrenal medulla, and carcinoma of the thyroid might appear to be fortuitous. Although both are rare conditions, there is an increasing number of reports of the two occurring in the same patient. Recently E. D. Williams ${ }^{1}$ has brought forward strong evidence that the two are connected. He reviewed 21 cases, including two of his own. The patients differ from those with either a phaeochromocytoma or a thyroid carcinoma in a number of ways. For example, the adrenal medullary tumour is bilateral in two-thirds of them, yet it is so in only $6 \%$ of cases of phaeochromocytoma without thyroid carcinoma. ${ }^{2}$ There is a familial incidence of phaeochromocytoma in about half the patients and of thyroid cancer in over a third. The interesting feature of the thyroid disease is the histological appearance of the tumour, which in at least thirteen of the cases was of the medullary type, normally extremely rare. This is characterized by sheets of tumour cells separated by a homogeneous material which has the staining properties of amyloid; there is no attempt at formation of follicles.

There seems therefore to be no reasonable doubt that there is an association between phaeochromocytoma and the medullary type of carcinoma of the thyroid. Either disease may precede the other in the individual patient, and it seems unlikely that one stimulates the production of the other. A more reasonable view, supported by the familial incidence, is that both are genetically determined. An association

\footnotetext{
1 Williams, E. D., f. clin. Path., 1965, 18, 288.

${ }^{2}$ Hume, D. M., Amer. 7. Surg., 1960, 99, 458.

Glushien, A. S., Mansuy, M. M., and Littman, D. S., Amer. F. Med., 1953, 14, 318 .

4 Masheter, H. C., Brit. med. F., 1963, 2, 1518.

5 Wermer, P., Amer. 7. Med., 1963, 35, 205.

- Brit. med. f., 1960, 1. 1873.
} 